\title{
Towards a computational model for stimulation of the Pedunculopontine nucleus Marcel AJ Lourens ${ }^{* 1}$, Hil GE Meijer ${ }^{1}$, Tjitske Heida ${ }^{2}$ and Stephan A van Gils ${ }^{1}$
}

\author{
Address: ${ }^{1}$ Department of Applied Mathematics, University of Twente, Enschede, $7500 \mathrm{AE}$, the Netherlands and ${ }^{2}$ Department of Electrical \\ Engineering, University of Twente, Enschede, $7500 \mathrm{AE}$, the Netherlands \\ Email: Marcel AJ Lourens* - m.a.j.lourens@utwente.nl \\ * Corresponding author
}

from Eighteenth Annual Computational Neuroscience Meeting: CNS*2009

Berlin, Germany. 18-23 July 2009

Published: 13 July 2009

BMC Neuroscience 2009, I0(Suppl I):P282 doi:I0.I |86/I47|-2202-I0-SI-P282

This abstract is available from: http://www.biomedcentral.com//47/-2202//0/SI/P282

(c) 2009 Lourens et al; licensee BioMed Central Ltd.

\section{Introduction}

The pedunculopontine nucleus (PPN) has recently been suggested as a new therapeutic target for deep brain stimulation (DBS) in patients suffering from Parkinson's disease, particularly those with severe gait and postural impairment [1]. Stimulation at this site is typically delivered at low frequencies in contrast to the high frequency stimulation required for therapeutic benefit in the subthalamic nucleus (STN) [1].

Despite real therapeutic successes, the fundamental physiological mechanisms underlying the effect of DBS are still not understood. A hypothesis is that DBS masks the pathological synchronized firing patterns of the basal ganglia that characterize the Parkinsonian state with a regularized firing pattern. It remains unclear why stimulation of PPN should be applied with low frequency in contrast to the high frequency stimulation of STN. To get a better understanding of PPN stimulation we construct a computational model for the PPN Type I neurons in a network.

\section{Methods}

Persistent sodium current is responsible for subthreshold membrane oscillations in PPN Type I neurons, which underlies spontaneous repetitive firing [2]. The low threshold spikes, which are responsible for bursts, are mediated by T-type calcium current [2]. In addition, the PPN model contains a leak, a sodium, a potassium and a hyperpolarization-activated current. The PPN Type I cell is modeled as a single compartment model using the Hodg-
kin-Huxley formalism, except for the calcium current, which is described by the Goldman-Hodgkin-Katz ion current equation.

\section{Results}

The model of PPN type I shows firing patterns as found in literature [2]: Burst after a period of hyperpolarization and spontaneous firing of $10 \mathrm{~Hz}$. Bifurcation analysis reveals that there is a bistability between high and low frequency tonic spiking.

\section{Discussion}

PPN plays a role in the control of the muscle tone by means of its excitatory projections to the muscle tone inhibitory system in the brainstem. In Parkinson's disease the inhibitory basal ganglia output is overactive. An increase in basal ganglia inhibition, together with a decrease in cortical excitation of the PPN, may increase the level of muscle tone (rigidity) [3].

Our next step will be to incorporate the PPN model in a Basal ganglia network and to investigate the effects of DBS on the behavior of the network. In particular: we shall analyze the output to the brainstem and describe the effects on the muscle tone. We shall also investigate combined stimulation of STN and PPN. 


\section{Acknowledgements}

The authors gratefully acknowledge the support of the BrainGain Smart Mix Programme of the Netherlands Ministry of Economic Affairs and the Netherlands Ministry of Education, Culture and Science.

\section{References}

I. Plaha P, Gill SS: Bilateral deep brain stimulation of the pedunculopontine nucleus for Parkinson's disease. Neuroreport 2005, 16:1883-1887.

2. Takakusaki K, Kitai ST: Ionic mechanisms involved in the spontaneous firing of tegmental pedunculopontine nucleus neurons of the rat. Neuroscience 1997, 78:77/-794.

3. Takakusaki K, Saitoh K, Harada H, Kashiwayanagi M: Role of basal ganglia-brainstem pathways in the control of motor behaviors. Neurosci Res 2004, 50:137-15I.

Publish with Bio Med Central and every scientist can read your work free of charge

"BioMed Central will be the most significant development for disseminating the results of biomedical research in our lifetime. "

Sir Paul Nurse, Cancer Research UK

Your research papers will be:

- available free of charge to the entire biomedical community

- peer reviewed and published immediately upon acceptance

- cited in PubMed and archived on PubMed Central

- yours - you keep the copyright

Submit your manuscript here:

http://www.biomedcentral.com/info/publishing_adv.asp 